\title{
Service level and Value to Customer as key business drivers: a case studying a leader truck industry
}

\author{
Maximiliano Cascini', Manuela Maini' ${ }^{1}$, Thiago Barroero ${ }^{3}$ \\ ${ }^{1}$ Workshop Development Manager, Customer Service, Iveco S.p.a. \\ maximiliano.cascini@iveco.com \\ ${ }^{2}$ Department of Computer Engineering and Systems Science, University of Pavia, \\ Italy maini.manuela@gmail.com \\ ${ }^{3}$ Department of Computer Engineering and Systems Science University of Pavia, \\ Italy thiagobarroero@gmail.com
}

\begin{abstract}
Since customer satisfaction analysis traditional approaches are out-ofdate and do not adequately fit information about customer expectations on services, in this paper we propose a new theoretical approach: the Customer Experience Management. Moreover this paper describes our analysis on the perceived value by customer according to the services that a company supplies. This analysis presents two different approaches: the qualitative and the quantitative one. Therefore we here define innovative way of studying customer satisfaction using both kind of analysis. Basing on the information gathered from the qualitative analysis, we develop a quantitative model to estimate and confirm the causal relations between process Key Performance Indicators. Finally we discuss a case study that demonstrates how we have applied our methodology to a multinational company operating in the automotive industry: Iveco. Specifically the case study focuses on Iveco Customer Service. Our customer value analysis enables management measuring and monitoring return on investments starting from the customer satisfaction and profitability analysis.
\end{abstract}

Keywords: Service Science, Management and Engineering (SSME), Customer Experience Management (CEM), Value to Customer, Business Intelligence, benchmarking.

\section{Introduction}

In our service era the value of the service to the customer is a structural driver of business. Therefore we think that a framework that relates the value given to the 
customer by service operations and the investments and technology spent on developing such service operations should be a key topic in the service science as defined in the well known paper on communication [6]. The value given to customer in service operations is especially critical in those industries where business has a long lasting relation with customers and high loyalty implies higher profitability. This is actually true in durable goods and machinery industries, where the customer care cycle is a structural component of the business and customer frustration may eventually imply churn.

When the business is strongly linked to the value perceived by the customer, as in our case study, tacit knowledge on this value can be considered related to the wishes and expectations that supplier should satisfy. In this case the supplier should understand what is the source of the value perceived by the customer in order to focus investments on it. This view revolutionizes the traditional concept of "Customer Value" and "Customer Satisfaction". Customer value described by a flood of papers is nothing else that the profitability that the customer seen as an asset, generates for the business. Our assumption is that customer value, specifically life time value is nothing else but the end outcome of the ability of the enterprise of satisfying customer expectations. The value perceived by the customers is the cause and life time value is the fact. Similarly, customer satisfaction is a measure that is highly discretionary and might portray what the analyst would like to listen $[13,18]$.

According to this perspective our analysis is based on one of the most innovative approaches on managing customers needs, namely Schmitt's Customer Experience Management (CEM) [19, 20].

CEM suggests new ways of capturing customer satisfaction and loyalty through innovative approaches to the customers and innovative ways of managing information on customers at any level of the organizations. Managing the whole customer experience is the best way for gaining actual satisfaction of customers. CEM implies the ability of enabling feelings of arousal and pleasure in customers. These motivating forces determine purchase choices, which are strongly driven by feelings and not only by material and functional needs of the customers.

\section{The analysis framework}

The analysis framework includes two analysis stages, respectively qualitative analysis and quantitative analysis.

Qualitative analysis consists of a framework that propose a cause-effect chain that links some input variables (investments) and output variables, that describe customer experience, and finally financial outcomes that describe the business impact of the customer experience.

Quantitative analysis is nothing else than a validation of qualitative analysis. It is based on statistical models that identify and estimate links between variables. 
Here below we give a short account of the structure of quantitative and qualitative frameworks.

\subsection{Qualitative framework}

The qualitative analysis is based on a questionnaire. In this way we have identified KPI (Key Performance Indicators) for each process of the chain. Among the KPI we have focused on those mostly linked to the value perceived by the customer. Every KPI represents different activity supplied by the firm, therefore we have focused on those that enable perceived value to grow up and to outwear. Afterwards we have assumed causal relations between the variables in the chain. For each KPI we have defined metrics, formed by elementary variables, in order to estimate them in the following step of the analysis.

Causal chains are a very innovative approach of representing causal relations between the KPI that describe the activities and the processes of a firm, since they clearly show the directions of the causality. The validity of the information given by the causality chains is strengthened by the numerical results of the Quantitative Model.

Figure 1 represents overall and specific (darker) variables of the service chain.

\begin{tabular}{|l|c|c|c|}
\hline $\begin{array}{l}\text { Investment } \\
\text { Variables }\end{array}$ & $\begin{array}{c}\text { Process \& System } \\
\text { Behavior }\end{array}$ & $\begin{array}{c}\text { Customer's Value } \\
\text { Variables }\end{array}$ & $\begin{array}{c}\text { Financial } \\
\text { Variables }\end{array}$ \\
\hline & & &
\end{tabular}

Fig. 1. Customized variables based on the Industry

We here discuss the main features of our case study (trucks):

1. Investment Variables

HR Educational

Technology capability 
2. Process \& System Behavior Variables

Promise

TA e TR

Contact duration

Customer's incurred cost

3. Customer's value Variables

Customer's value

New Customers

Churn

Customer Loyalty

Profitability

4. Financial Variables
$\Delta$ Asset
$\Delta \mathrm{LTV}$

AGP

Specifically the Value chain in Fig.2. is customized on Iveco after-sale service processes and it represents causal relations between their KPI.

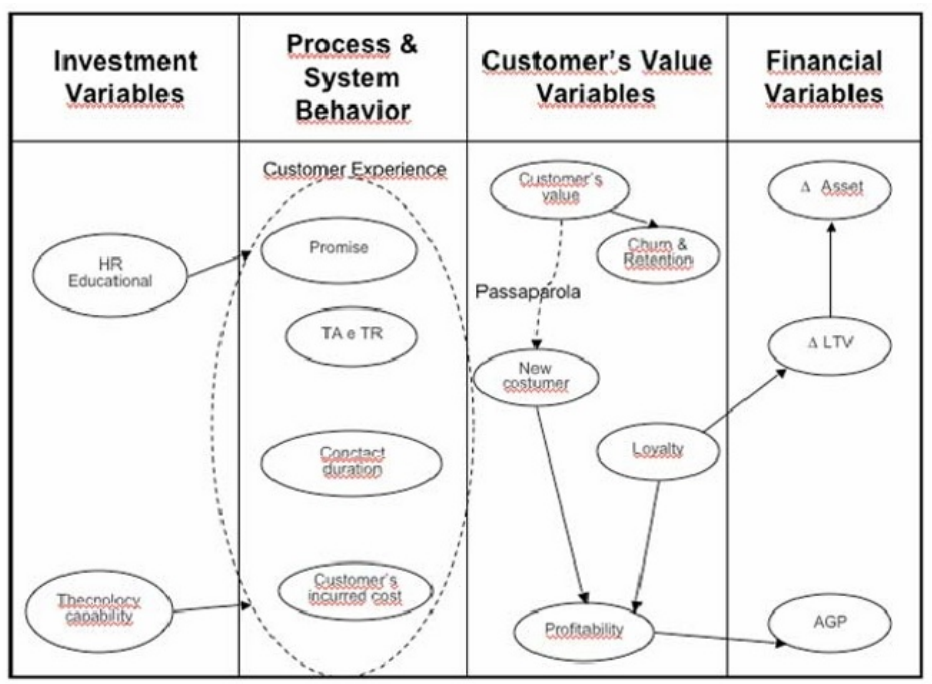

Fig.2. Customized Iveco Value Chain

Starting from this chain quantitative analysis should have to confirm and estimate those causal links that concretely exist and influence the return on the investments that the company has done to capture customer satisfaction and loyalty. 


\subsection{Quantitative analysis}

The quantitative model estimates the causal relations identified by the qualitative analysis.

Interpreting and understanding the quantitative model results from the customer point of view will enable us to affirm which investments really influence customers behaviour and as a result determine rises in customers profitability. Therefore it is clear that such an analysis allows the company to measure return on investments through the analysis of the variables representing customer experience and satisfaction and linking them to the firm supplied activities.

The quantitative model includes two main statistical tools: Granger's causality model [3, 9] and the Latent Variables Structural Equations (LVSE) [21, 23]. These tools have been used in parallel to analyse the historical series of data associated to each variable. The quantitative model is represented in the following Figure 3.

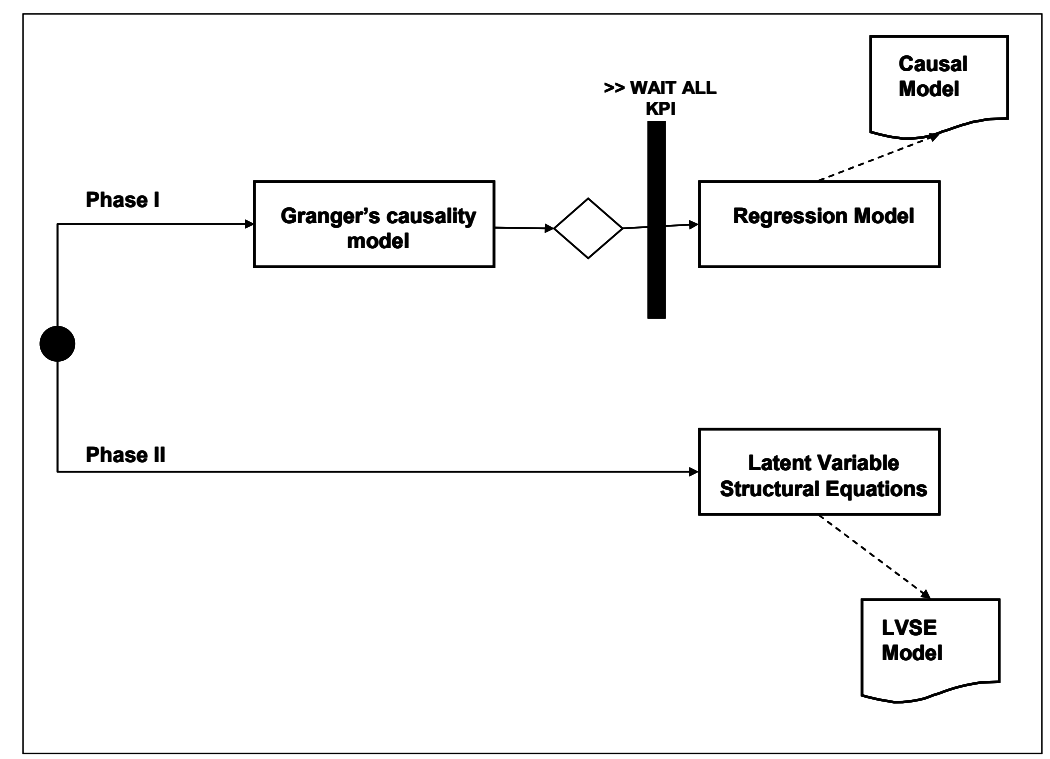

Fig. 3. Quantitative Analysis Model

Granger's causality model has been selected since it greatly deals with time series of data in order to test out whether a causality relation exists between two variables represented through their time series of data. Then we have used the Linear Regression method to estimate the effectiveness of the existing relations [21].

As our main scope, using Granger's causality model [9], we would like to understand if one variable influences an other variable. Especially we are mostly interested in identifying those investment variables that significantly influence the 
customer perceived value, increasing customer satisfaction. In this way the company can address its investment more accurately toward those activities that boost customer satisfaction.

The analysis methodology makes use of a comparison between the knowledge achieved considering a pair of variables and their relation rather than the piece of information given by each variable individually considered. The strength of the identified relations stands for the capability of a variable to explicate the other one in the pair.

As described our interest is focused on the customer perceived value, which is a variable that cannot be directly observed since it is intangible and immaterial. Whereupon we have introduced also the Latent Variables Structural Equations (LVSE) in the quantitative model [23].

LVSE is a model that allows to study those variables not mentioned in the value chains since they are non-observable but whose influence can be identified analysing their indicators behaviour. Non-observable variables are defined as latent variables.

Value to Customer is the latent variable we have analysed: it is about the value the customers perceive making use of after sales services supplied by Iveco. So, as subsequently deepened, the attention of the study focuses on the Customer Service and the treated series of data come from the Non-Stop Assistance service delivered by Iveco Customer Centre.

The advantages a corporate can gain through "Value to Customer Analysis" are extremely important according to today market dynamics. In fact customers are more and more pretentious and exigent since they can manage lots of information regarding anything they need or they are searching for. Therefore companies need to affected customers. It means that it is not enough thinking only to the supply functional aspects instead companies have to know what are the emotional sides to invest in to render the customer experience extraordinary, unforgettable obtaining customer satisfaction for a longer period measured by the life time value associated to each customer.

\section{The case study}

Iveco [24] is a multinational company operating in the automotive industry.

Service business accounts the $25 \%$ of the whole turnover of the company and it is composed both by Iveco Capital and Customer Service.

Iveco is present with its After Sales Services in America, Europe, Africa and Middle East Asia Pacific with 3.000 service points, 22 spare parts warehouse, 50.000 specialists, 10 millions spare parts orders per year, 300.000 Iveco original spare parts for all the Iveco brands. 


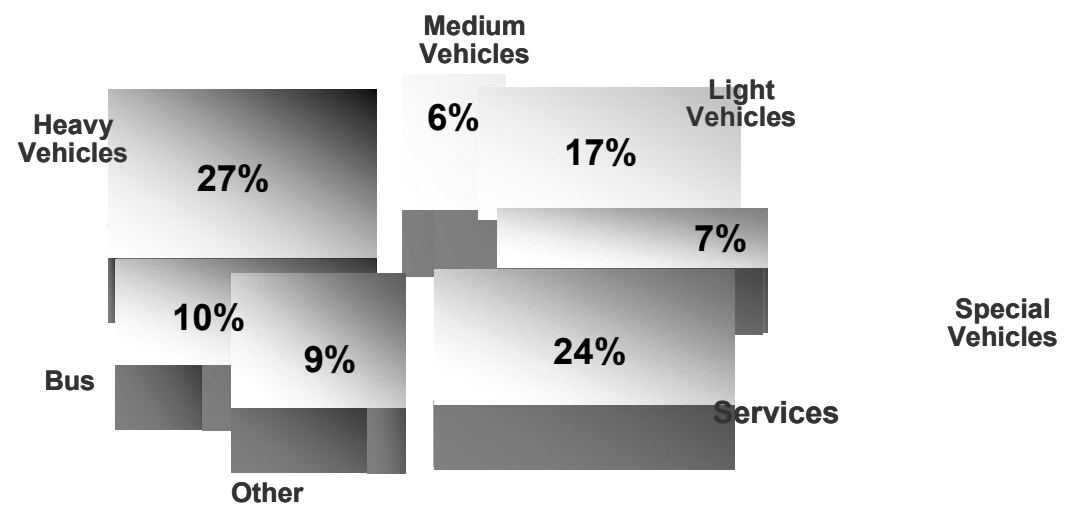

Fig. 4. Iveco Departments

The Iveco "Customer Service" has a network capable of reaching the Iveco customers needs of service all over the world. The Customer Service can be considered as a "company in the company", which is composed both by line activities and staff activities.

Line activities include three main lines:

1. the Sales and marketing line;

2. the Supply Chain line;

3. the Service line.

In general we can say that Sales and marketing and Supply Chain lines deal with spare parts whereas the Service line deals with diagnostic and repair activities.

Firstly we can consider the Sales and marketing line; its scope is to sale original Iveco spare parts, since these parts are the higher guarantee of the brand quality. The sale is driven by focused campaign both on the functional and on the emotional aspects of the product according to the Customer Experience Management principles. 


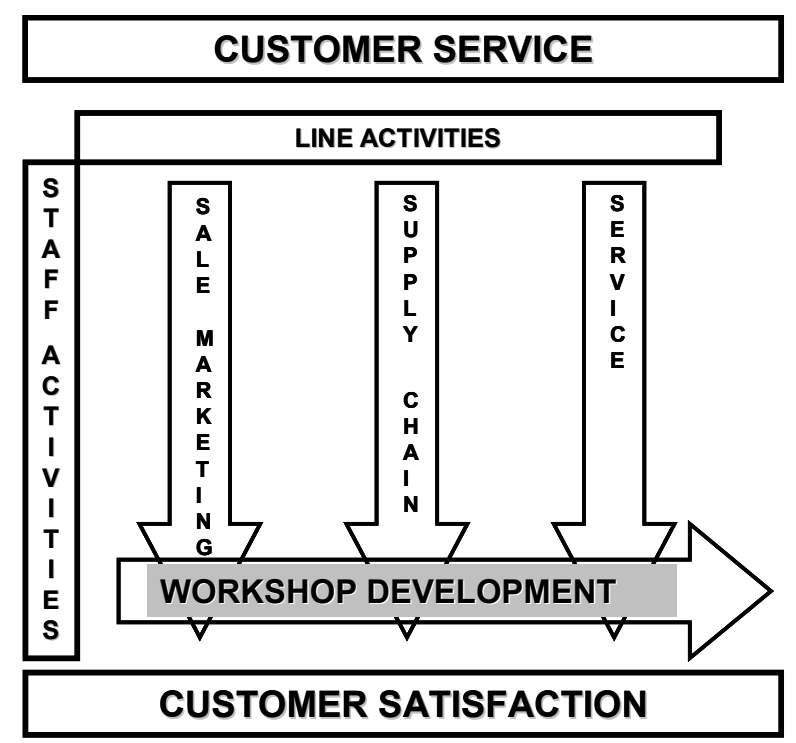

Fig. 5. Iveco Customer Service general structure

A second line is the Supply Chain whose scope is to make available spare parts in good times trough the Iveco workshops network all around the world with monitoring stock levels at a central Iveco warehouses and in the workshops warehouses and then to supply stocks with great managing of times.

The third line is the Service one; its scope is that of granting excellent quality of diagnostic and repairing capability. Therefore Service line deals with:

specializing staff with technical education: Iveco has created a team of specialized mechanics that periodically meet to share solutions to the strangest and most difficult problems (DEEC);

projecting innovative instruments to diagnose failures easier, more precisely and in a shorter time;

building the "telediagnostic" service, as a support of expertise mechanics for those mechanics who reaching trucks in pain can not find a solution to the failure; defining standardized levels that every international workshop has to perform, such as the schedule for the different interventions.

In addition to the quality of the spare parts, granted by the Sales and marketing line, it is fundamental to emphasize the importance of finding well-trained mechanics since they are able to solve problems in a better way and in a shorter time; in this second case the Service line need to grant to our mechanics a high quality training. It means that the different lines have to interact to deliver the best quality level of service, in this way people is sure that original spare parts are installed by specialized and well trained mechanics. This great interaction between Service and Supply Chain lines assure a high quality level of the service and 
consequently customer satisfaction rises up. In fact the quickness of repairs will make customer satisfaction to grow up whereas great managing of stocks will increase our dealer satisfaction.

Furthermore Customer Service lines cooperate with some Head Quarters Staff Departments whose activities and projects are oriented to generate customer satisfaction. HQ Staff Departments include Human Resources, Finance, Administration and so on.

Among the HQ staff organisations we will here focus on the activities of Workshop Development whose scope is to manage and organize the service network.

Workshop Development works to find the suitable composition of service network to satisfy customer needs through:

- designing a proper coverage network, equally distributed in the country at an international level;

- monitoring the mechanics training in order to optimize the performances of the assistance, both in terms of efficiency and effectiveness of interventions;

- defining quality standards to ensure the same services in every workshop in the European area;

- managing workshop development. Workshops are the entities that pragmatically enclose every activity of lines. Therefore where and how the workshops are located is fundamental. For example whether they are more or less reachable deeply influences customer satisfaction;

- thinking different kind of services depending on the type of customers; since satisfaction comes from different sources depending on the customers target. For example, whether the market refers to "Daily" (light trucks) rather than to "trucks" (heavy Trucks) the needs of customers are strongly different: truck customers are willing to travel even longer distances to find the best Service Points for their vehicle, instead Daily customers desire higher coverage and specificity of workshops to reach them and solve problems in a shorter time.

These features lead customer oriented Workshop Development management. So we can see that Workshop Development requires compromises in terms of feasibility to fit the needs of different categories of customers. These compromises should be sustainable either for the customer, for the company and for the network.

An example of this trade off is given by the "isocrones": it is a study made by Iveco called TAS that analyses the main vehicles trades and fluxes and defines the minimum presence of workshops on the basis of 45 minutes to get from the Service Network to any points in the main routes in Europe $24 \mathrm{H}$ a day 7 days a week. 


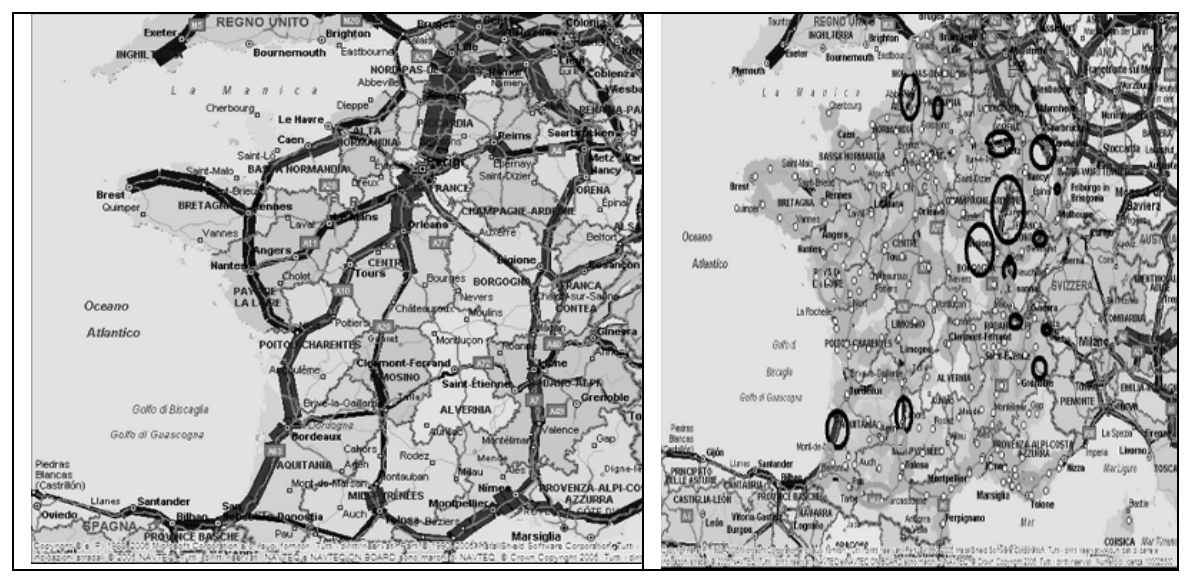

Fig. 6. Main routes and critical points identified through the TAS project

The scope of the TAS (Top Assistant Service) project is to build an adequate structure to deliver a great service level supporting customer into situations of difficulty. Therefore TAS project has as a target to increase the level of Iveco assistance service, allowing both the customer satisfaction and the corporate and workshop profitability to increase.

Iveco Workshop Development also sets and repeatedly monitors the standards for its workshops quality level.

Through these activities the Workshop Development assures excellent level of the customer assistance and simultaneously monitors the profitability achieved through service delivery both for the corporate and the workshops.

So Workshop Development helps Iveco and its service network to manage the trade-off between developing customer satisfaction and making profit.

Iveco delivers the Non-Stop Assistance service through the Customer Centre. The Non-Stop Assistance service is characterised by over $50 \%$ of cases resolved within 3 hours after reporting the fault, $80 \%$ within 7 hours. This service is valid for the whole truck life and for any model Iveco, under warranty or out of warranty.

The Non-Stop Assistance service is based on the monitored critical items and it aims to improve customer trust facing toward the sensitive problems. Therefore TAS project is aimed at recognising the main European traffic routes and guaranteeing the international customer an Assistance Network with adequate territorial coverage, a higher standard of quality and excellent level of service.

Periodic monitoring of performance standards makes the authorized workshops an element allowing higher quality Service level.

The partnership Iveco with its workshops is fundamental to deliver high performance service level. Since workshops can be considered as an interface between the corporate and the customers, it is very important that Iveco and its 
Workshops are linked by a win-win relation of partnership. It means that each side should obtain positive results through the delivered services.

In this way the mission of the Workshop Network is oriented to create, develop and maintain a service network assuring the highest level of service quality to guarantee a profitable partnership with Iveco while satisfying customer expectations. Such a context gives a competitive advantage to Iveco in comparison to the competitors.

The main scope of this study on Iveco Customer Service is to test out whether investments on Customer Relationship Management (CRM) give the expected results.

The analysis allows to understand which elements affect Customer Satisfaction, since we suppose that customer satisfaction is increased through service higher quality level. The causality analysis enables to identify the investment indicators that cause the higher customer profitability.

The analysis is performed using the Quantitative Model that analyses the causality correlations between KPI in the value chain.

Particularly the analysis focuses on the Iveco Non-Stop-Assistance service process and on the activity of the Customer Centre. Every day of the year, 24 hours on 24, in 25 countries in Europe and outside Europe, a team made up of over 80 trained persons is available to solve truck drivers problems.

Through the chassis number of the vehicle, the operator identifies in real-time the truck and its technical characteristics. Then they identify what kind of anomaly affects the truck; so the operator organises the speech, identifying and calling the closest and most suitable workshop to whom to entrust the vehicle. Whether necessary Non-Stop Assistance service provides handling of perishable or dangerous goods. Finally through a series of telephone services Iveco follows the client until the completion repairing of the vehicle.

More precisely the Non-Stop Assistance Service is delivered following specific steps.

First of all an operator receives calls and when needed he opens a dossier grounding the assistance procedure. Each dossier contains a contact history that makes it possible to track all inbound and outbound calls on the same issue.

Depending on the kind of failure he decides which is the best workshop to activate. Iveco scope, according to TAS project, is to activate workshop in no more than 15 minutes and to reach the truck in no more than 45 minutes.

Basing on this stream of activities we have identified the process variables and their causal correlations. We have assumed the investments on Customer Centre technology and on staff training as correlated to the customers perceived value. Therefore the analysis focuses on three main areas of interest, whose variables have been studied.

The areas of interest are:

1. calls: this area refers to Customer Centre performances;

2. staff dimensions: this variable represents the investment on call centre;

3. dossier: theirs KPI refer to the non-stop-assistance service performances. 
The selected time series of data symbolizing the Customer Centre activities concern one year of observations.

Calls have been segmented in function of the place of breakdown and of the truckdriver spoken language. Then for each dossier we have analyzed all the information about workshop, failure and assistance management.

In accordance with the hypothesis the analysis expects to confirm that "Value to Customer" is higher whether time to repair is kept the shortest it is possible.

During the analysis we paid attention in taking care of the market target since for different markets there are different customers needs and expectations.

Measured variables compose the metrics for the KPI; so the following variables describe the analysed main processes.

The selected variables regarding Calls process are:

- calls total number;

- missed calls;

- waiting time;

- surrender time.

Each variable has been segmented according to the dimensions of: data (yy-mm$\mathrm{dd}$ ), time (hh), language (= client area), breakdown area (= workshop area).

The selected variables regarding Staff dimensions are:

5. operators number: measured as daily mean of operators.

This variable has been segmented according to the dimensions of: data (yy-mm$\mathrm{dd}$ ), time (hh) and language (= client area).

The selected variables regarding Dossier are:

- time to assistance: measured as difference between the arrival time on breakdown area and the calling time;

- time to repair: measured as difference between the arrival time in the workshop and the vehicle delivery time;

- detected rate of repairs: measured as ratio between the reported repairs and the total number of calls to Customer Centre.

These variables have been segmented according to the dimensions of: data (yymm-dd).

- Number of calls: measured as the calls number needed to solve a dossier.

This variable has been segmented according to the dimensions of: data (yy-mmdd), inbound calls number, outbound calls number, client code.

- Daily number of opened dossiers.

This variable has been segmented according to the dimensions of: data (yy-mm$\mathrm{dd})$, time (hh), language (= client area), breakdown area (= workshop area), breakdown market (= client market) and truck model.

The output of the quantitative analysis model, represented in Figure 7, defines which relations exist between the investment variables and the customer perceived 
value basing on the relations existing among the studied variables. Since value to customer is a latent variable the model provides its indicators too, even accounting the evaluation of the relation between the latent variable and each indicator.

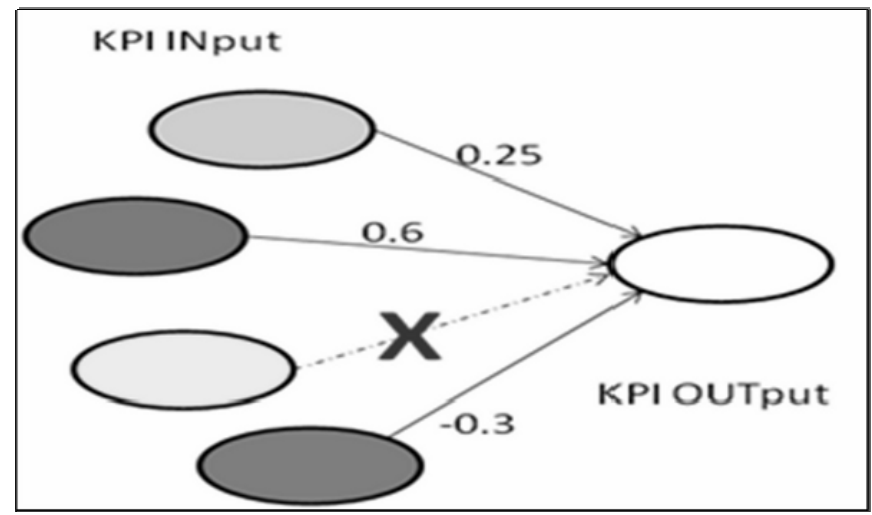

Fig. 7. An example of the Quantitative Model Output

In the end through the analysis Iveco can improve its awareness on how much value and importance customers associate to the supplied services. It is fundamental to know that piece of information in order to manage services development trying to reach customer satisfaction.

The whole analysis, according to the paradigm of CEM, is built around the customer need and expectation, both in terms of technology innovation and of the bid emotional aspects. Since our main scope has been to verify the concrete return on investments sustained to deliver to the customers services with the highest quality level.

\section{Conclusions}

The research of qualitative framework is highly beneficial for companies because it allows to explicit customer experience. Validation can be made by a variety of approaches that include test-groups, quantitative analysis on a sample of customers, extensive data mining. Our approach is to use a selective quantitative analysis to test and validate qualitative assumption and therefore to set a quantitative investment model in customer service. Further development might include a research project by which a panel of companies in a given industry (e.g. automotive) compare and benchmark their customer service practices. Such a panel allows to improve practice and engineer viable services identifying those services that meet customers needs and expectations. Actually, for management is 
critical to assess the return on investments, not to waste funds and time in campaigns that do not raise interest and loyalty from target customers.

Furthermore the analysis allows a deeper understanding of the customers which are the key asset for any service industry. Customers drive service economy : serving their attitudes is a must to improve competitiveness and reach a sustainable advantage.

Our research is now dealing with quantitative results that identify the actual value cluster represented by process variables.

Acknowledgments Authors will thank SAS for the financial and technical support that specially included software used for the analysis and that made research possible.

\section{References}

1. Addis M, Holbrook M (2001) On the Conceptual Link Between Mass Customisation and Experiential Consumption: An Explosion of Subjectivity. Journal of Consumer Behavior. An International Research Review, Vol.1, 5066

2. Addis M (2005) L'esperienza di consumo. Analisi e prospettive di marketing, I ed. Pearson, Milano

3. Ashley R, Granger CWJ, Schmalensee R (Jul., 1980) Advertising and Aggregate Consumption: An Analysis of Causality. Econometrica, Vol. 48, No. 5, 1149-1167

4. Bracchi G, Francalanci C, Motta G (2005) Sistemi informativi per l'impresa digitale. MacGraw-Hill, Milano

5. Carbone LP, Haeckel SH (1994) Engineering Customer Experience. Marketing Management, Vol.3, Issue 3

6. Chesbrough H, Spohrer J (July, 2006) A Research for Services Science, Communication of the ACM, Vol.49, N.7, 35-40

7. De Nicolao G, Scattolini R (1997) Identificazione Parametrica. CUSL

8. Ferraresi M, Schmitt BH (2006) Marketing esperienziale. Come sviluppare l'esperienza di consumo, I ed. FrancoAngeli, Milano

9. Granger CWJ, Newbold P () Forecasting Economic Time Series. New York: Academic Press

10.Hamilton JD (1994) Econometria delle Serie Storiche. Monduzzi Editore

11.Hirschman EC (August, 1986) Humanistic Inquiry in Marketing Research: Philosophy, Method and Criteria. Journal of Marketing, Vol.23, No. 3, 237-249

12.Hirschman EC, Stern BB The Roles of Emotion in Consumer Research. In Advances in Consumer Research Volume 26, Eds. Arnould EJ and Scott LM, Provo, UT: Association for Consumer Research, 4-11 
13.Hirschman EC, Holbrook MB (Summer, 1982) Hedonic Consumption: Emerging Concepts, Methods and Propositions. Journal of Marketing, Vol.46, N. 3, 92-101

14.Hirschman EC, Holbrook MB (1986) Expanding the Onthology and Methodology in Consumer Research on the Consumption Experience. In Brinberg D, Lutz RJ(Eds.), Perspectives on Methodology in Consumer Research, Springer-Verlag, New York, 213-251

15.Holbrook MB (June, 1987)What is Consumer Research?. The Journal of Consumer Research, Vol.14, No.1, 128-132

16.Holbrook MB (1999) Introduction to Customer Value. In Holbrook MB (Ed.), Consumer Value: A Framework For Analysis and Research, Routledge, London, 1-28

17.Holt DB (June, 1995) How Consumers Consume: A Typology of Consumption Practice. The Journal of Consumer Research, Vol. 22, No. 1, 1-16

18.Pine JBII, Gilmore JH (1999) The Experience Economy. Work Is Theatre \& Every Business a Stage. Harvard Business School Press, Massachusetts, Boston 19.Schmitt BH (1999) Experiential Marketing. How to get consumers to SENSE, FEEL, THINK, ACT and RELATE to Your Company Brands. The Free Press (eds.), New York

20.Schmitt BH (2003) Customer Experience Management. A revolutionary Approach to Connecting with Your Customers. Hoboken NJ, John Wiley \& Sons

21.Verbeek M (2006) Econometria, Zanichelli

22.Vercellis C (2006) Business Intelligence. Modelli matematici e sistemi per le decisioni. McGraw-Hill, Milano

23.SAS INSTITUTE INC. (2004) SAS/ETS_ 9.1 User's Guide. Cary, NC: SAS Institute Inc.

24.www.iveco.com 